\title{
Effects of Rare Earth (Ce and La) on Steel Corrosion Behaviors under Wet-Dry Cycle Immersion Conditions
}

\author{
Xintong Lian ${ }^{1,2, *}$, Jianan Zhu ${ }^{1,2}$, Ruiqian Wang ${ }^{1,2}$, Tengshi Liu ${ }^{1,2}$, Jing Xu ${ }^{1,2}$, Dexiang Xu ${ }^{2,3}$ \\ and Han Dong 1,2 \\ 1 State Key Laboratory of Advanced Special Steel, Shanghai University, Shanghai 200444, China; \\ zhujianan@shu.edu.cn (J.Z.); wrq00002@shu.edu.cn (R.W.); liutengshi@shu.edu.cn (T.L.); \\ kinghsu86@shu.edu.cn (J.X.); 13910077790@163.com (H.D.) \\ 2 School of Materials Science and Engineering, Shanghai University, Shanghai 200444, China; \\ xudexiang009@sina.com \\ 3 Shanghai University New Materials (Tai Zhou) Research Institute, Taizhou 225500, China \\ * Correspondence: xtlian@shu.edu.cn; Tel.: +86-182-4036-2077
}

Received: 5 August 2020; Accepted: 20 August 2020; Published: 1 September 2020

\begin{abstract}
Rare earth (RE) elements are beneficial to improving corrosion properties in low-carbon and low-alloy steels. In this paper, corrosion performance of Q235B steel and Q355B steel samples after RE alloying under wet-dry cycle immersion conditions were analyzed. Experimental results show that corrosion rate was significantly decreased. It was probably due to the grain refinement by RE alloying, which increased the density of protective rust layers and improved corrosion resistance. The formation of small-sized spherical RE inclusions also inhibited the precipitation of MnS and weakened micro galvanic corrosion. Additionally, RE atoms tended to segregate towards grain boundaries and a RE concentration region is formed between rust layers and matrix to impede the access from contacting corrosive ions. A corrosion resistance schematic of RE atom segregation was proposed based on microstructure morphology and element distribution results.
\end{abstract}

Keywords: rare earth; immersion tests; inclusion; segregation; microstructure

\section{Introduction}

Low-carbon and low-alloy steels have been widely used as structural materials due to their excellent engineering properties. However, when these two kinds of construction steels exposed to atmospheric corrosion environment, they are prone to be attacked and corrosion will result in potential safety problems and economic losses [1,2]. Many methods including multi-alloying, coatings and inhibitors have been investigated to decelerate the steel corrosion [3-6]. Among them, multi-alloying is an effective method to decrease destructive corrosion. Valid chemical elements such as $\mathrm{Cu}, \mathrm{P}, \mathrm{Cr}$ and $\mathrm{Ni}$ are proved effective in preventing atmospheric corrosion with a rising cost $[3,7,8]$. Considering the economic and environmental reasons, attention has been paid to the development of cheaper alloying technologies applied to materials.

In recent years, many studies have shown that rare earth (RE) elements can not only purify molten steels but also modify inclusions due to their strong affinity for oxygen and sulfur [9,10]. Inclusions are considered to have negative effects on the corrosion properties of steels [11]. The atmospheric corrosion originates from pitting corrosion and spreads to the entire surface to form uniform corrosion. It is well-known that manganese sulfide (MnS) often provides initiation sites for pitting corrosion and aluminium oxide $\left(\mathrm{Al}_{2} \mathrm{O}_{3}\right)$ has also been considered to cause destructive effects on corrosion resistance of steels [12-14]. The addition of RE has been reported to capture sulfur to form RE inclusions and inhibits the formation of $\mathrm{MnS}[11,15,16]$. In addition, RE element is active and probably enriched 
at the interfaces such as grain boundaries or surfaces due to the big difference of atomic radius between RE and iron [17-19]. The microstructure and corrosion properties are changed because of the concentration of RE elements at grain boundaries, which affects the diffusion of other elements and restrain the nucleation and growth of new phases $[20,21]$. RE also segregates towards interfaces, which is considered as the micro-alloying effect, though it differs from what is commonly thought as solid solution effect.

Although many investigators have shown effects of RE elements on microstructure and inclusions in steels, few studies have focused on the influence of RE alloying such as segregation of RE atoms in steels under wet-dry cycle immersion conditions. Two common construction steels including Q235B and Q355B steels were chosen to be the experimental steels. This paper elucidates how $\mathrm{RE}$ increased the corrosion performance under wet-dry cycle immersion tests. Scanning electron microscopy-energy dispersive spectroscopy (SEM-EDS), electron probe microanalysis (EPMA) and auger electron spectroscopy (AES) were conducted to investigate the mechanism of improving corrosion resistance by the method of RE alloying.

\section{Experimental}

Two kinds of steels were selected as experimental samples marked as Q235B and Q355B. A certain amount of RE elements ( $\mathrm{Ce}$ and $\mathrm{La}$ ) were added into these two modified steels and were marked as Q235BM and Q355BM. The alloys were melted into ingots and then hot rolled into steel plates $(300 \mathrm{~mm} \times 1000 \mathrm{~mm})$. The average chemical composition of final experimental steels is listed in Table 1 .

Table 1. Chemical composition of experimental steels (wt\%).

\begin{tabular}{ccccccccccc}
\hline Sample & $\mathbf{C}$ & $\mathbf{S i}$ & $\mathbf{M n}$ & $\mathbf{P}$ & $\mathbf{S}$ & $\mathbf{C r}$ & $\mathbf{A l}$ & $\mathbf{C u}$ & $\mathbf{C e}$ & La \\
\hline Q235B & 0.12 & 0.09 & 0.34 & 0.019 & 0.009 & 0.024 & 0.022 & 0.023 & - & - \\
\hline Q235BM & 0.12 & 0.08 & 0.34 & 0.020 & 0.010 & 0.023 & 0.022 & 0.023 & 0.018 & 0.0065 \\
\hline Q355B & 0.14 & 0.23 & 1.15 & 0.020 & 0.007 & 0.023 & 0.039 & 0.020 & - & - \\
\hline Q355BM & 0.13 & 0.23 & 1.15 & 0.020 & 0.007 & 0.023 & 0.039 & 0.020 & 0.011 & 0.0041 \\
\hline
\end{tabular}

Three parallel samples $(45 \mathrm{~mm} \times 55 \mathrm{~mm} \times 3 \mathrm{~mm})$ were prepared for calculating the rate of corrosion weight loss under wet-dry cycle immersion tests. Immersion tests were undertaken at $45^{\circ} \mathrm{C}$ in a solution of $0.01 \mathrm{~mol} / \mathrm{L} \mathrm{NaHSO}_{3}$. One immersion cycle included $15 \mathrm{~min}$ of infiltration and $45 \mathrm{~min}$ of exposure. The test durations were determined as $24 \mathrm{~h}, 48 \mathrm{~h}, 96 \mathrm{~h}$ and $144 \mathrm{~h}$. Before immersion tests were conducted, the specimens were cleaned ultrasonically and weighed in a dry environment. Part of rust was scraped off for X-ray diffractometer (XRD) analysis. After corrosion products were removed, the specimens were weighed to determine the mass loss. The rest rust on the surface were chemically moved in a specific solution $(500 \mathrm{~mL} \mathrm{HCl}+500 \mathrm{~mL}$ distilled water $+3.5 \mathrm{~g}$ hexamethylenetetramine). After corrosion products were removed, the specimens were weighed to determine the mass loss.

Metallographic images were observed by optical microscopy (OM). The morphology of inclusions was observed using a thermal field scanning electron microscopy (SEM) and combined with energy dispersive X-ray spectroscopy (EDS). The surface micro-corrosion morphology of samples after $144 \mathrm{~h}$ of immersion tests was observed. Cross sections of the specimens were mounted in epoxy resin and sprayed with gold. Electron Probe Microanalysis (EPMA) was determined to quantitatively measure chemical composition of phases and element distribution of rust layers. The impact specimens of Q235BM and Q355BM were subjected to an impact test to obtain a brittle fracture at the temperature of $-20{ }^{\circ} \mathrm{C}$. The in-situ scanning Auger Electron Spectroscopy (AES) was used to analyze the change of RE concentration at different sputtering depths from the fracture surface. The ion beam with the energy of $2 \mathrm{keV}$ covered an area of $2 \mathrm{~mm} \times 2 \mathrm{~mm}$ and sputtered at intervals of $0.5 \mathrm{~min}$. 


\section{Results and Discussion}

Figure 1 displays the change of surfaces morphology during immersion tests. It is observed that double rust layers are formed on the surfaces of these steels. The outer rust layer is a porous rufous or tawny solid, while the inner layer is a dense black solid. It is found that more pores and local exfoliating of outer rust layer appear on the sample surface in Q235B and Q355B steels with the extension of test time. Observed from the sides of sample, the rust layer in Q235B and Q355B steels turns thicker obviously. Whereas, the rust layers of Q235BM and Q355BM steels are much thinner than those of Q235B and Q355B steels and are mainly composed of compact dark solid with a little loose tawny solid on the surface.
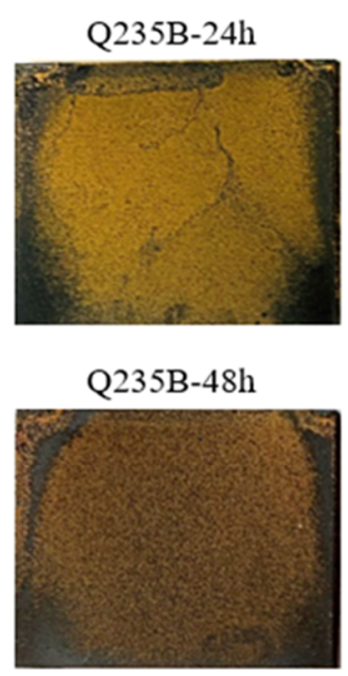

Q235B-96h

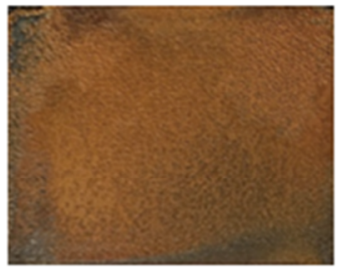

Q235B-144h

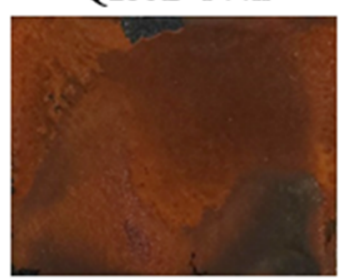

Q235BM-24h

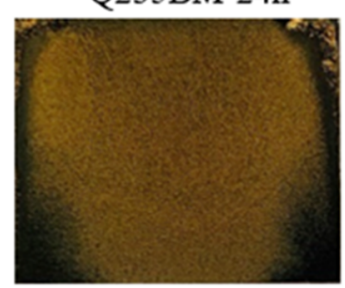

Q235BM-48h

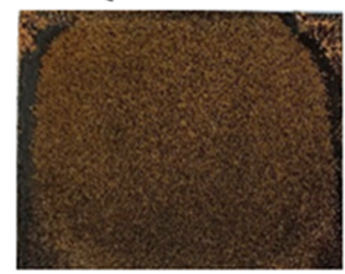

Q235BM-96h

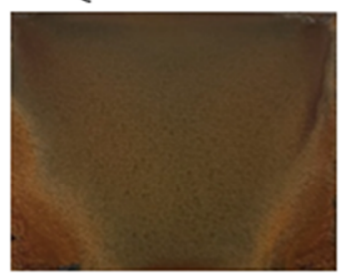

Q235BM-144h

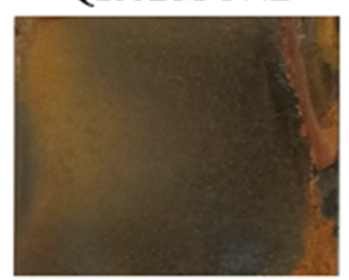

Q355B-24h

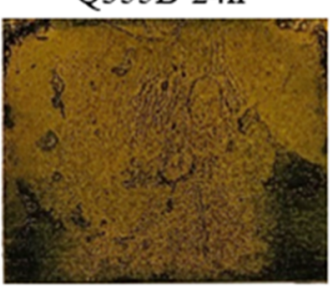

Q355B-48h

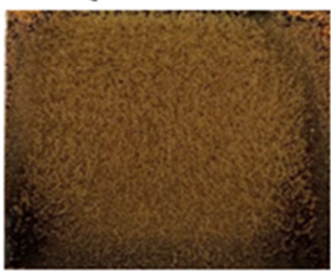

Q355B-96h

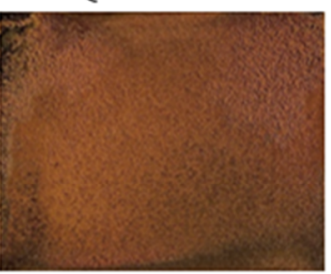

Q355B-144h

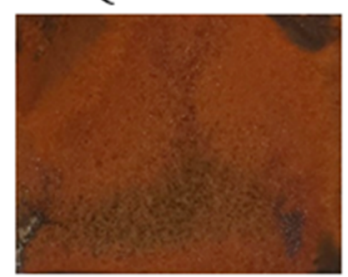

Q355BM-24h

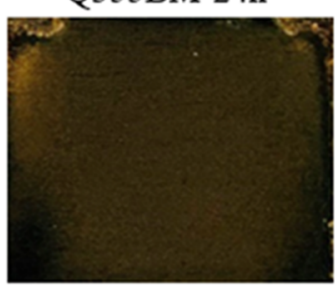

Q355BM-48h

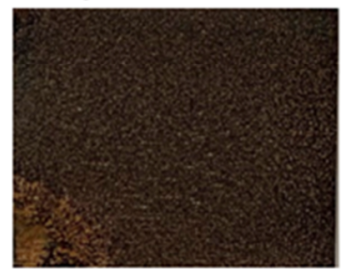

Q355BM-96h

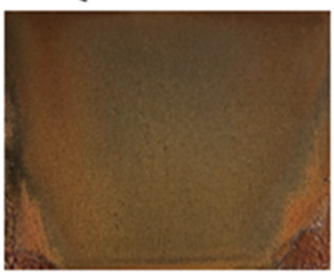

Q355BM-144h

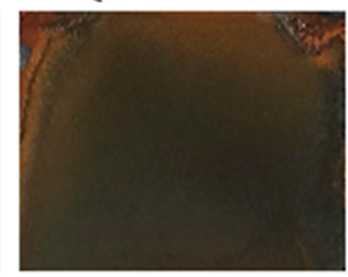

Figure 1. Surface morphology of sample rust layers after immersion tests (24-144 h).

Corrosion rates obtained in wet-dry cycle immersion tests are shown in Figure 2. The corrosion rates $\left(\mathrm{g} \cdot \mathrm{m}^{-2} \cdot \mathrm{h}^{-1}\right)$ of these four steels are calculated from the following Equation $(1)[22,23]$ :

$$
W=\frac{G_{0}-G_{1}}{S \times t}
$$

where $W$ means corrosion rate $\left(\mathrm{g} \cdot \mathrm{m}^{-2} \cdot \mathrm{h}^{-1}\right), G_{0}$ means initial weight of specimens before immersion test $(\mathrm{g}), G_{1}$ means weight of corroded specimens after removing surface corrosion products $(\mathrm{g}), S$ means initial total surface area of specimens $\left(\mathrm{m}^{2}\right), t$ means test time $(\mathrm{h})$. At the beginning of corrosion tests, corrosion rates of these two steels are high and tend to decrease with further corrosion due to a certain 
protective roles of rust layers formed on the surface [24]. Rust layers can effectively prevent the corrosive ions in the atmosphere from contacting the matrix. Corrosion rate of steels after RE alloying is lower than that before RE alloying. Furthermore, corrosion rate of Q355BM decreased faster than that of Q235BM, indicating RE alloying has a more obvious effect on low-alloy steels than low-carbon steels.

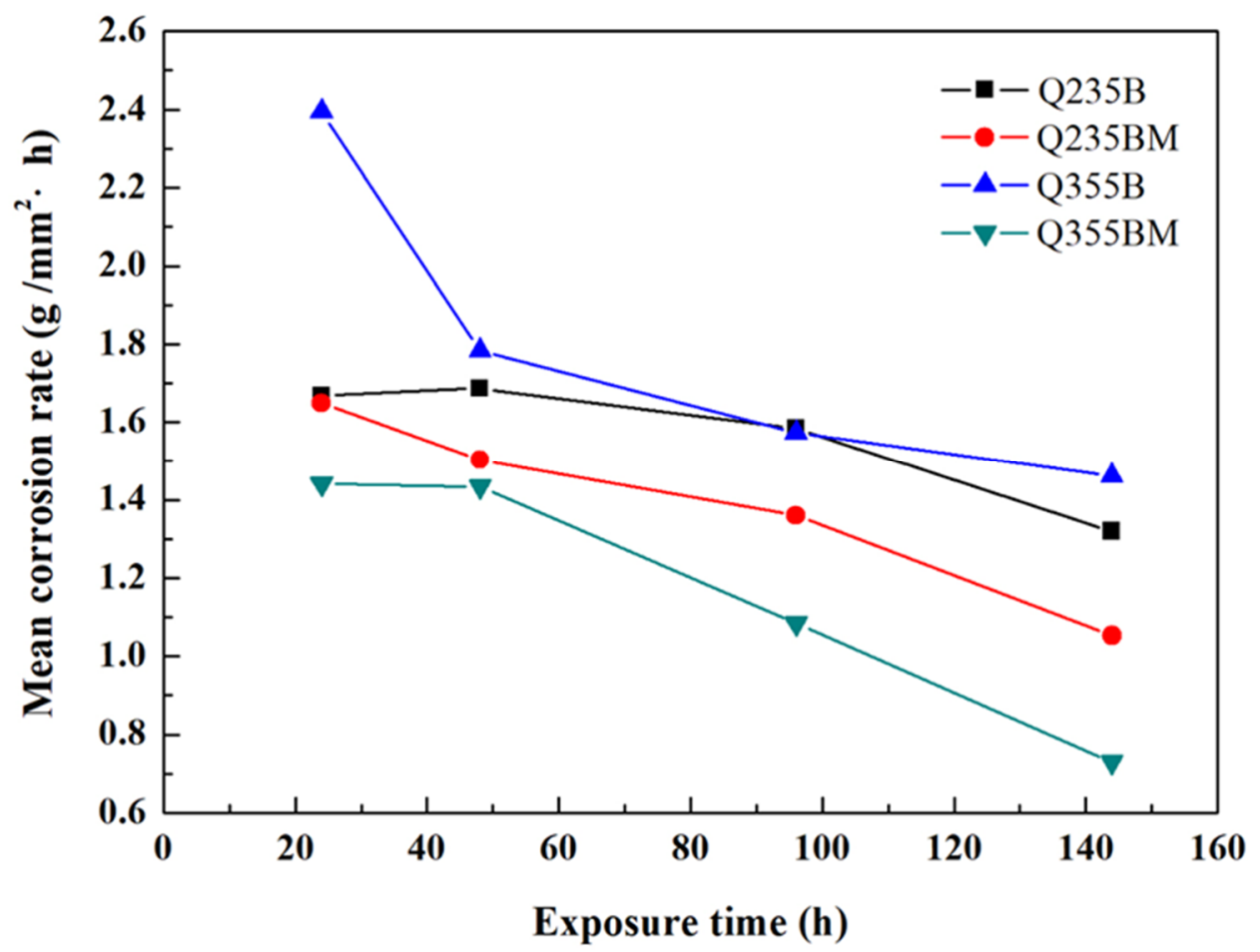

Figure 2. Corrosion rates obtained in wet-dry cycle immersion tests.

The morphology of oxide products on the surface of rust layers has been observed by SEM, as shown in Figure 3. The oxide particles on the surface in the samples of Q235B and Q355B steels are large and rough before RE alloying. In particular, the surface of rust layer in Q355B steel is leaky and some deep cracks are unevenly distributed on the surface. After the addition of $\mathrm{Ce}$ and $\mathrm{La}$, the surface oxidation products turn finer and are distributed uniformly, while the number of cracks and pores is obviously reduced. However, the rust layer is not easy to crack after RE alloying and has a strong ability to protect the matrix.

Figure 4 presents the $\mathrm{XRD}$ analysis of corrosion products. The main corrosion phases are all composed of $\gamma-\mathrm{FeOOH}, \alpha-\mathrm{FeOOH}, \mathrm{Fe}_{3} \mathrm{O}_{4}$ and $\gamma-\mathrm{Fe}_{2} \mathrm{O}_{3}$. According to previous study, $\gamma-\mathrm{FeOOH}$ is firstly formed and then transforms to $\alpha-\mathrm{FeOOH}$ and $\mathrm{Fe} 3 \mathrm{O} 4$ during the atmospheric corrosion of steels $[7,23,25,26] . \alpha-\mathrm{FeOOH}$ is the most stable hydroxy iron oxide and the main phase in protective rust layers. $\gamma-\mathrm{FeOOH}$ is an electrochemically active phase and has negative influence on the protection of rust layers in the initial stage of corrosion. It is difficult to determine accurately whether $\mathrm{Fe}_{3} \mathrm{O}_{4}$ and $\gamma-\mathrm{Fe}_{2} \mathrm{O}_{3}$ is a mixture or one compound due to their similarity of XRD patterns. The relative content of corrosion products is shown in Table 2. The proportion of $\alpha-\mathrm{FeOOH}$ is enhanced obviously, while the content ratio of $\gamma-\mathrm{FeOOH}$ is decreased after RE alloying. The content of $\mathrm{Fe}_{3} \mathrm{O}_{4}$ and $\gamma-\mathrm{Fe}_{2} \mathrm{O}_{3}$ is also improved. The corrosion products of rust layers gradually turn to stable products and protective effect on the matrix is strengthened after RE alloying. 

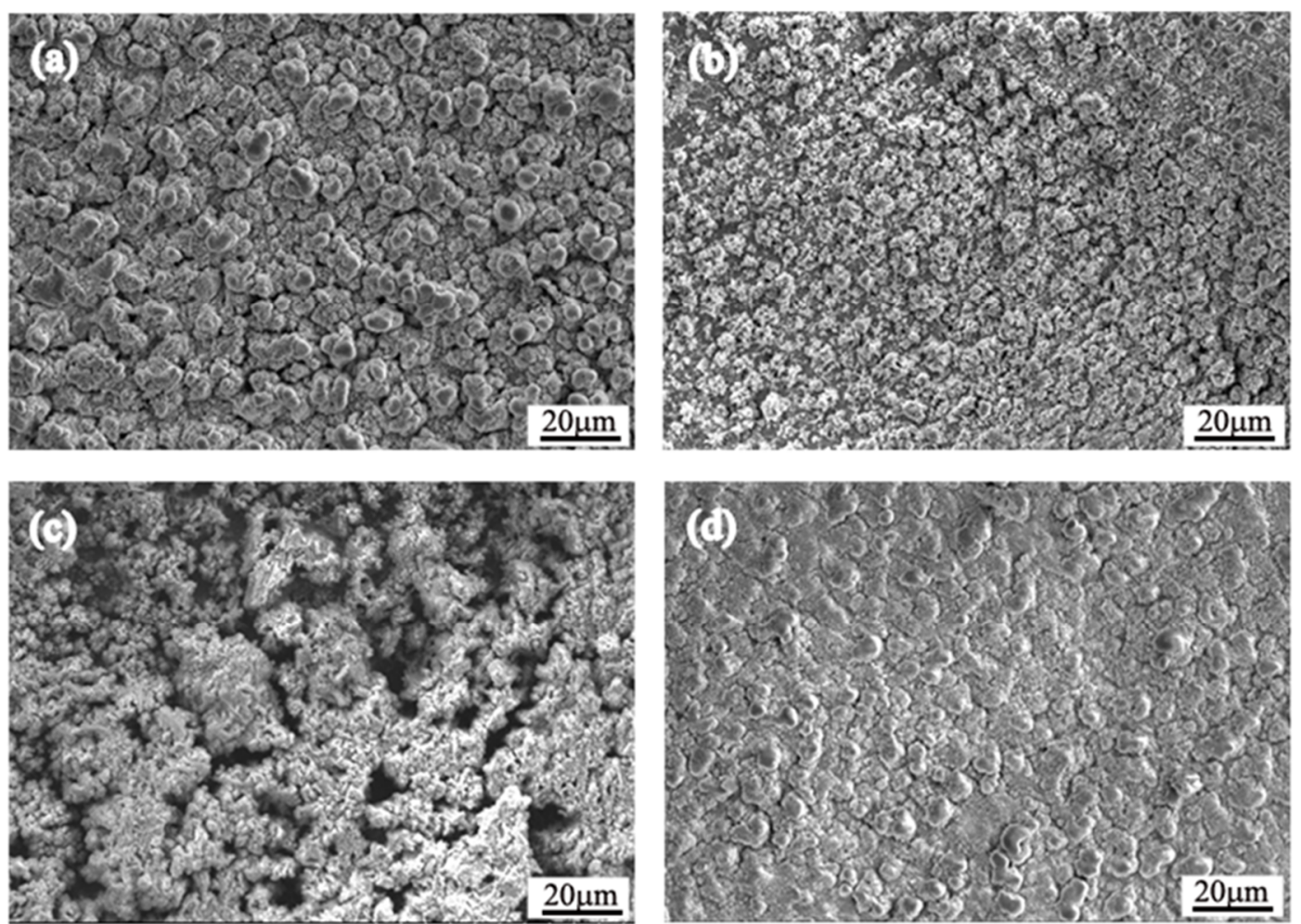

Figure 3. Oxide products on the surface of rusty samples after $144 \mathrm{~h}$ immersion tests (a) Q235B (b) Q235BM (c) Q355B (d) Q355BM.

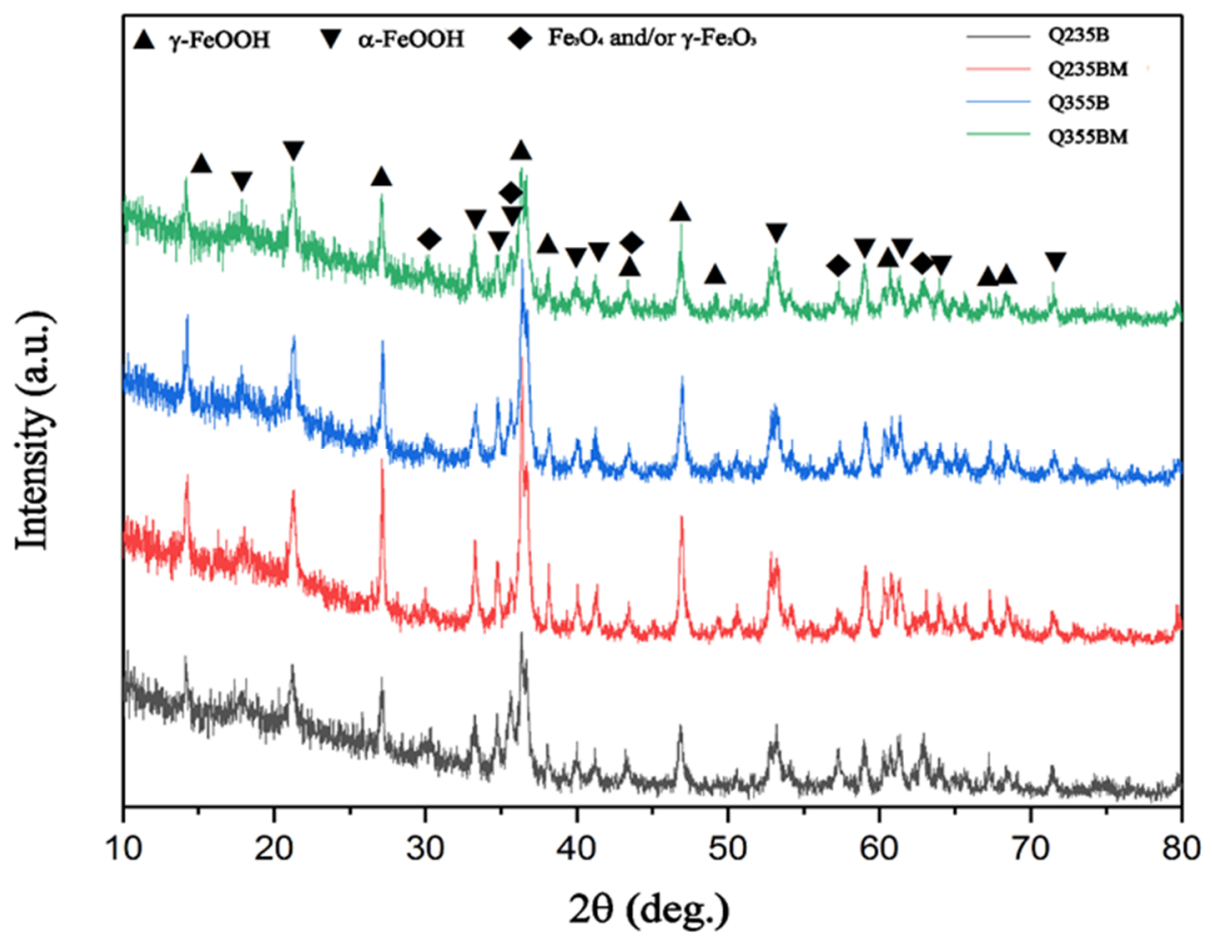

Figure 4. XRD analysis of corrosion products. 
Table 2. The relative content of corrosion products of steel samples.

\begin{tabular}{cccc}
\hline Sample & $\alpha$-FeOOH & $\gamma$-FeOOH & $\mathrm{Fe}_{3} \mathbf{O}_{4}$ or $/$ and $\boldsymbol{\gamma}-\mathrm{Fe}_{2} \mathbf{O}_{3}$ \\
\hline Q235B & $28 \%$ & $53 \%$ & $19 \%$ \\
Q235BM & $35 \%$ & $34 \%$ & $31 \%$ \\
Q355B & $17 \%$ & $63 \%$ & $20 \%$ \\
Q355BM & $44 \%$ & $23 \%$ & $33 \%$ \\
\hline
\end{tabular}

In order to clarify the existence of RE element, Figures 5 and 6 respectively show the cross-section morphology and elemental distribution in rust layers after $144 \mathrm{~h}$ immersion tests. The cross-sections are selected from the center of the sides of specimens where the rust layer is the thickest. Due to many cracks and defects existing in rust layers, some epoxy entered into rust layer during sample processing and brings in fluctuation of element obviously. The width of the thickest rust layer in Q235B and Q355B steels is about $150 \mu \mathrm{m}$, while the width is less than $100 \mu \mathrm{m}$ in Q235BM and Q355BM steels. In all steels, the content of $\mathrm{Al}$ and $\mathrm{Cr}$ in the loose surface rust layer and outer rust layer is low, while enriched peaks are found in inner rust layers. In Q235BM and Q355BM steels, the contents of Ce and La are much higher in matrix than in rust layers and obvious rising peaks are found near rust layers shown by red arrows. No RE inclusions is observed to gather towards the interface. Therefore, RE element probably has an obvious aggregation towards the interface in the form of atoms during corrosion process, forming a RE atom layer between rust layers and substrate.

Many researchers believe that RE atoms tend to segregate towards grain boundaries or interfaces such as surfaces or grain boundaries due to their large radius $[18,23]$. Whether segregation of RE elements towards interfaces occurs or not, an AES experiment has been performed for the specimens with RE addition to test this finding. A completely intergranular fracture surface covered by grain boundaries has been produced and the change of Ce content in each layer under different ion sputtering time is analyzed as shown in Figure 7. According to previous study, the kinetic energy range of Ce is chosen from $52 \mathrm{eV}$ to $115 \mathrm{eV}$ including three typical Auger peaks of $\mathrm{Ce}$ at $68 \mathrm{eV}, 87 \mathrm{eV}$ and $104 \mathrm{eV}$, respectively [23]. Although the spectra lines have a certain deviation from the standard map, the tested Auger peaks of Ce in Q235BM steel are at $68 \mathrm{eV}, 87 \mathrm{eV}$ and $103 \mathrm{eV}$, which are consistent with typical peaks in Auger Electron Spectroscopy Reference Manual [27]. For Q355BM samples, the Auger peaks are detected at $69 \mathrm{eV}, 89 \mathrm{eV}$ and $104 \mathrm{eV}$. It is certainly confirmed that Ce atoms gather towards fracture surface. After sputtering for $0.5 \mathrm{~min}$, the peak values of three characteristic peaks turn less obvious, which indicates that the content of Ce is decreasing. When sputtering at $1.0 \mathrm{~min}$, the peaks almost disappear because the content of Ce is too low to be detected. AES results show that the content of Ce elements on surfaces covered with grain boundaries is the highest and then decreases with the depth into grains. Whereas, no obvious Auger peaks of La are found by AES, although La atoms should have the similar Auger peaks as Ce atoms in theory. Previous study has explained this phenomenon due to the minimum level to be effectively detected and the difficulty to be distinguished from Ce [23]. Although the peaks of $\mathrm{La}$ are not obvious as $\mathrm{Ce}, \mathrm{La}$ atoms are still believed to segregate towards grain boundaries for its similar chemical properties to Ce atoms. 

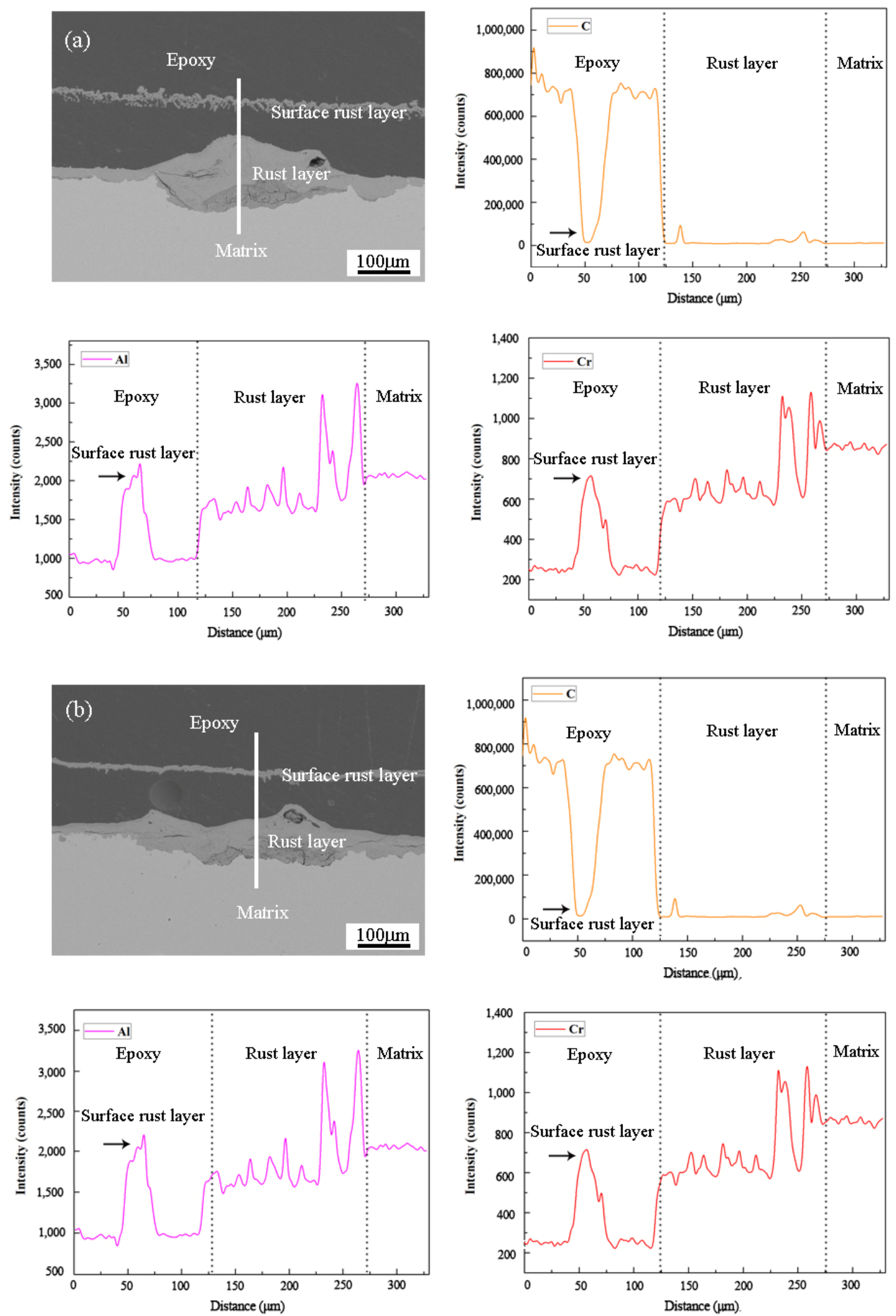

Figure 5. Element distribution in rust layers after $144 \mathrm{~h}$ immersion tests (a) Q235B (b) Q355B. 

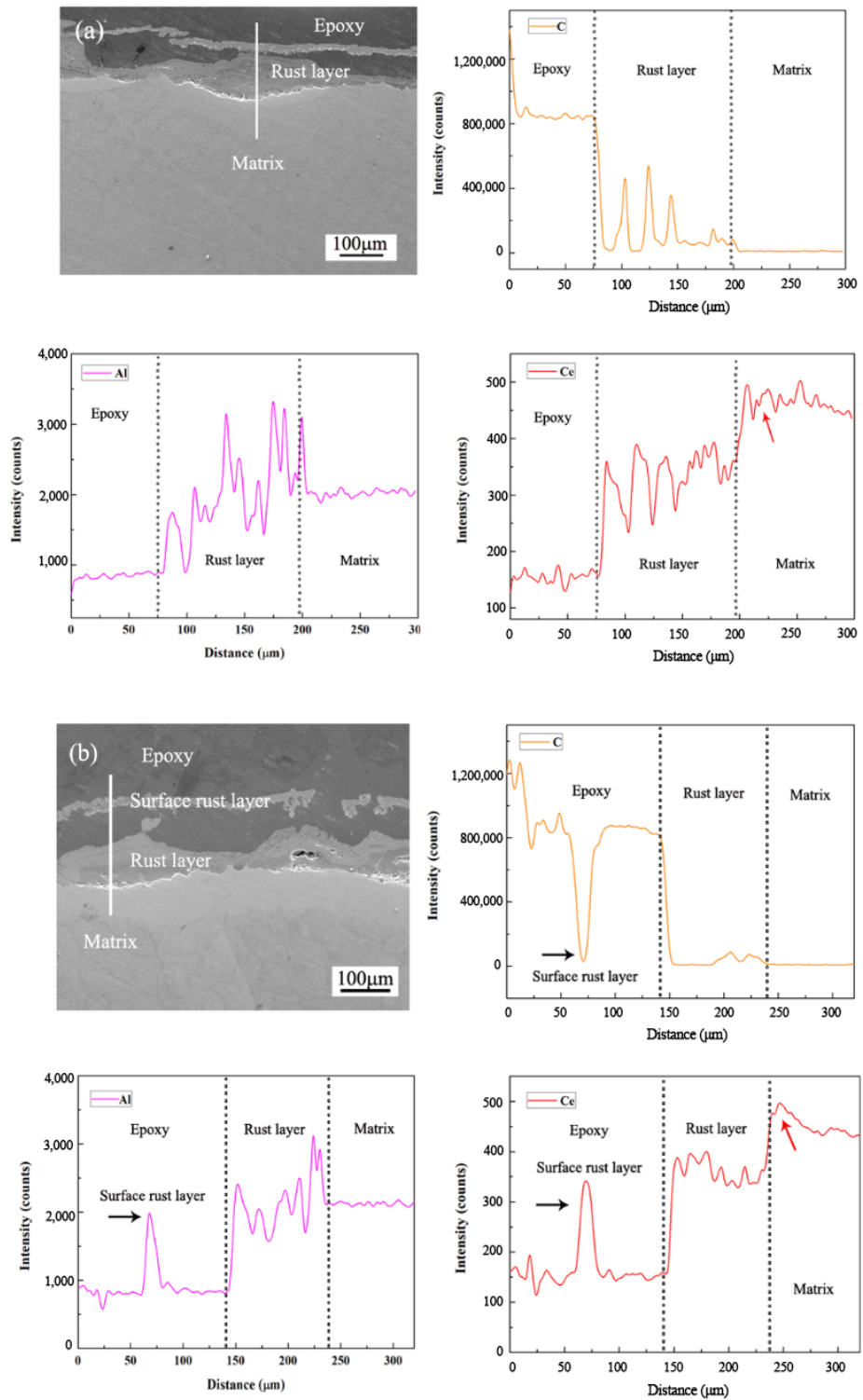
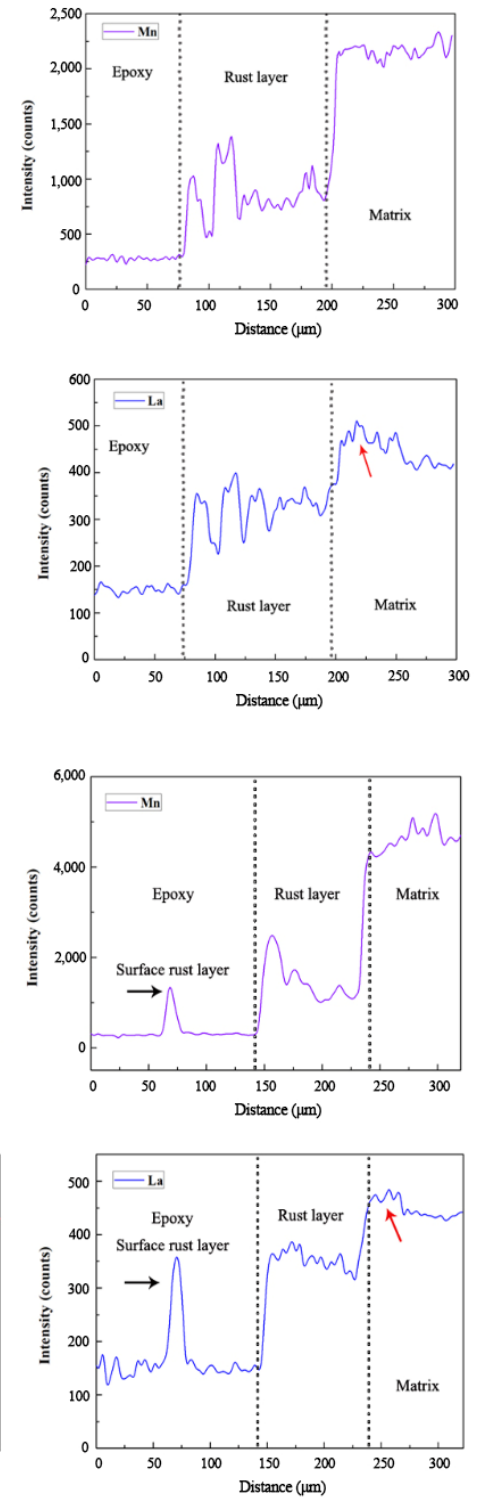

Figure 6. Element distribution in rust layers after $144 \mathrm{~h}$ immersion tests (a) Q235BM (b) Q355BM.

From the results of AES spectrum in Figure 7, it is certain that the phenomenon of RE segregation tends to occur in steels. Since the auger sputtering depth is limited to less than $2 \mathrm{~nm}$ under the surface, which is equivalent to several atomic layers, interfacial segregation of RE elements occupies only a few atomic layers [28]. The characteristics of RE segregation towards interfaces is beneficial to improve corrosion resistance of steels. In a cyclic corrosive environment, the corrosive ions can easily contact the matrix through rust layers to accelerate the corrosion of steels. Due to the differential dissolution of RE elements in matrix and in rust layer, RE elements begin to play a role in the formation and transformation process of rust layers. RE atoms will be preferentially enriched in the pores and defects at the interface under the action of micro current, segregating and forming a RE segregation region between the rust layer and the matrix. The formation of RE atom layer is beneficial to accelerate the healing of defects and block the channel between the corrosive medium and the matrix. In addition, the segregated RE atoms may also become the crystallization cores of the rusting phase, making the rust ions grow up slowly and promoting the density of rust layers [9,29]. Furthermore, the RE segregation region can also inhibit the aggregation of $S$ in the rust layer due to the strong affinity between $R E$ and $\mathrm{S}$, which improves the external environment and facilitates the rapid formation of protective rust layers $[10,30,31]$. 

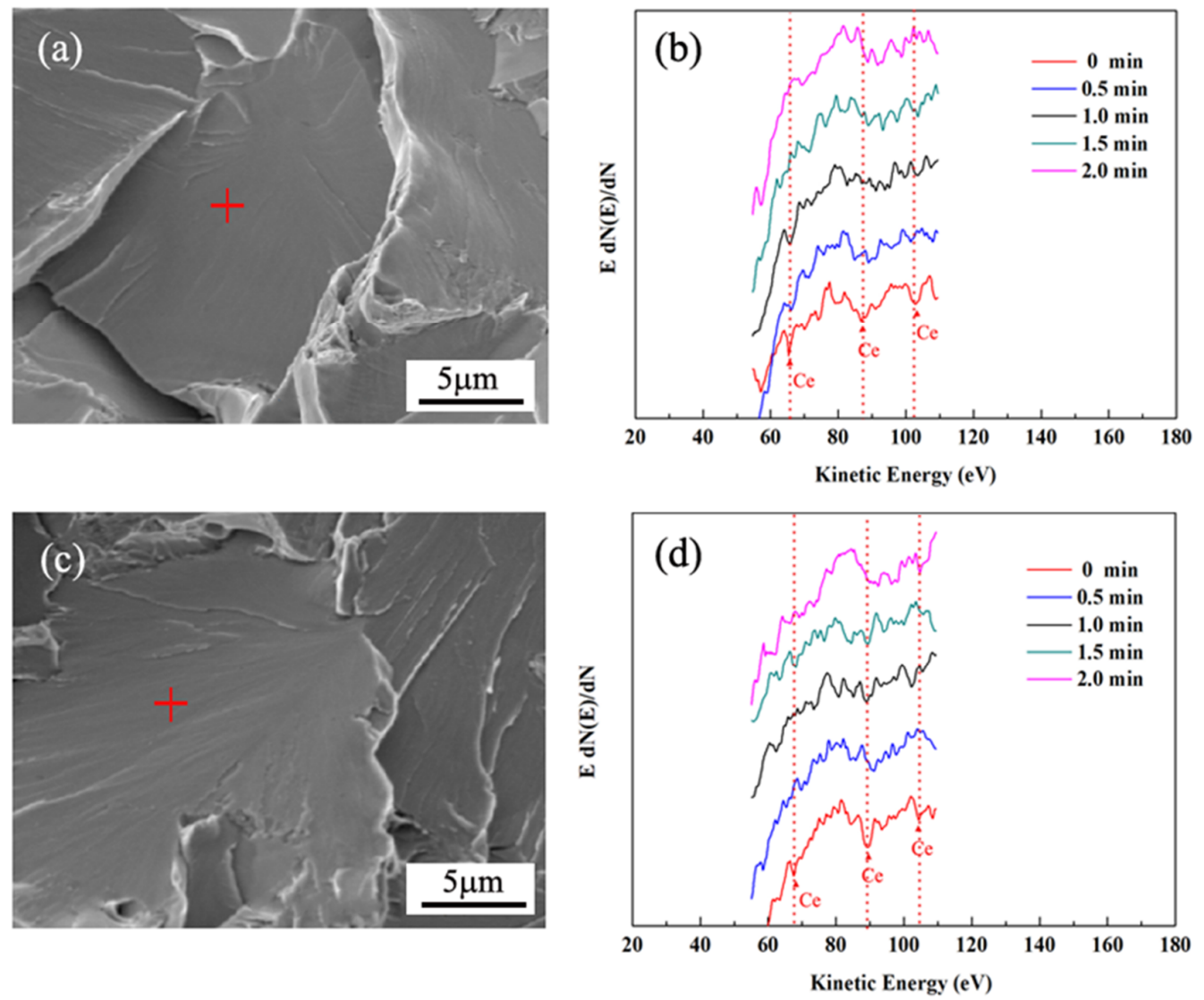

Figure 7. Intergranular impact fracture morphology (red plus sign marks the location where AES test is conducted) and AES spectrum of Ce in Q235BM (a,b) and in Q355BM (c,d).

Based on above analyses, the corrosion resistance schematic of RE segregation in steels is proposed in Figure 8. RE atoms migrate towards the interface to fill in the pores and defects between rust layer and matrix. A protective RE atom region is formed during the process of immersion tests. Before $\mathrm{RE}$ alloying in steels, corrosive ions can contact the matrix through pores and cracks in rust layers to continuously corrode the matrix as shown in Figure 8a. However, the segregated RE atoms fill in the pores and cracks, thus cutting the access and preventing the corrosive ions from further entering the matrix after RE alloying, as indicated in Figure 8b. It is beneficial to improve the compactness and adhesion of the rust layer and slow down the corrosion rate of the matrix by RE-alloying method. Nevertheless, further work should be conducted to determine if RE atom layer is stable or dissolved later and how RE atoms spread into rust layers with the increasing corrosion time.
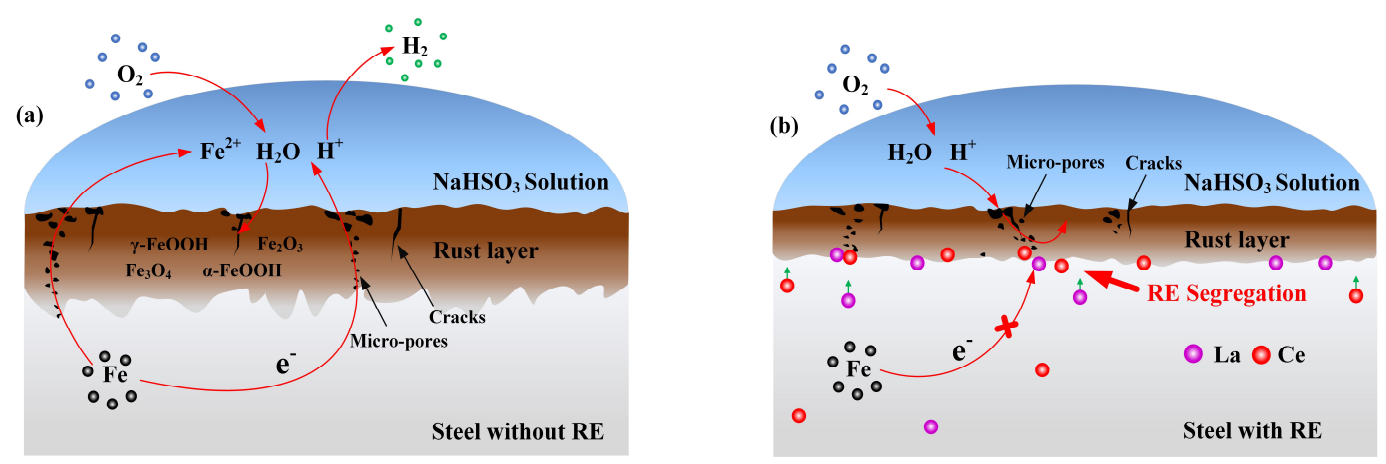

Figure 8. Schematic of RE atom layer preventing from corrosion (a) before RE alloying (b) after RE alloying. 
Besides, the increased corrosion properties after RE alloying is also closely related to microstructure refinement. Microstructure before and after RE alloying are shown in Figure 9. The matrix is composed of ferrite and pearlite. The average grain size has been estimated to be $23 \mu \mathrm{m}$ in Q235B steel and $15 \mu \mathrm{m}$ in Q235BM steel, while the average size is about $11 \mu \mathrm{m}$ in Q355B steel and $7 \mu \mathrm{m}$ in Q355BM steel. Effects of RE on grain refinement are firstly due to the increase of subcooling degree by RE addition, which improves the nucleation rate of austenite and refine grains [14-16]. In addition, RE oxysulfide can refine grains as smaller heterogeneous nucleation [15,17]. The segregation of RE can also prevent grain boundary from migrating and inhibit grain growth. Grain refinement is reported to decrease the number of metastable pits [32-34]. The reduction of grain size results in a decrease in the ratio of grain areas involved in the cathode reaction to the total areas of corrosion zone. The corrosion uniformity in refined grains is better and the probability of forming deeper cracks and cavities is smaller after $\mathrm{RE}$ alloying. Grain refinement can increase the density of rust layers, thus improving its resistance to atmospheric corrosion.
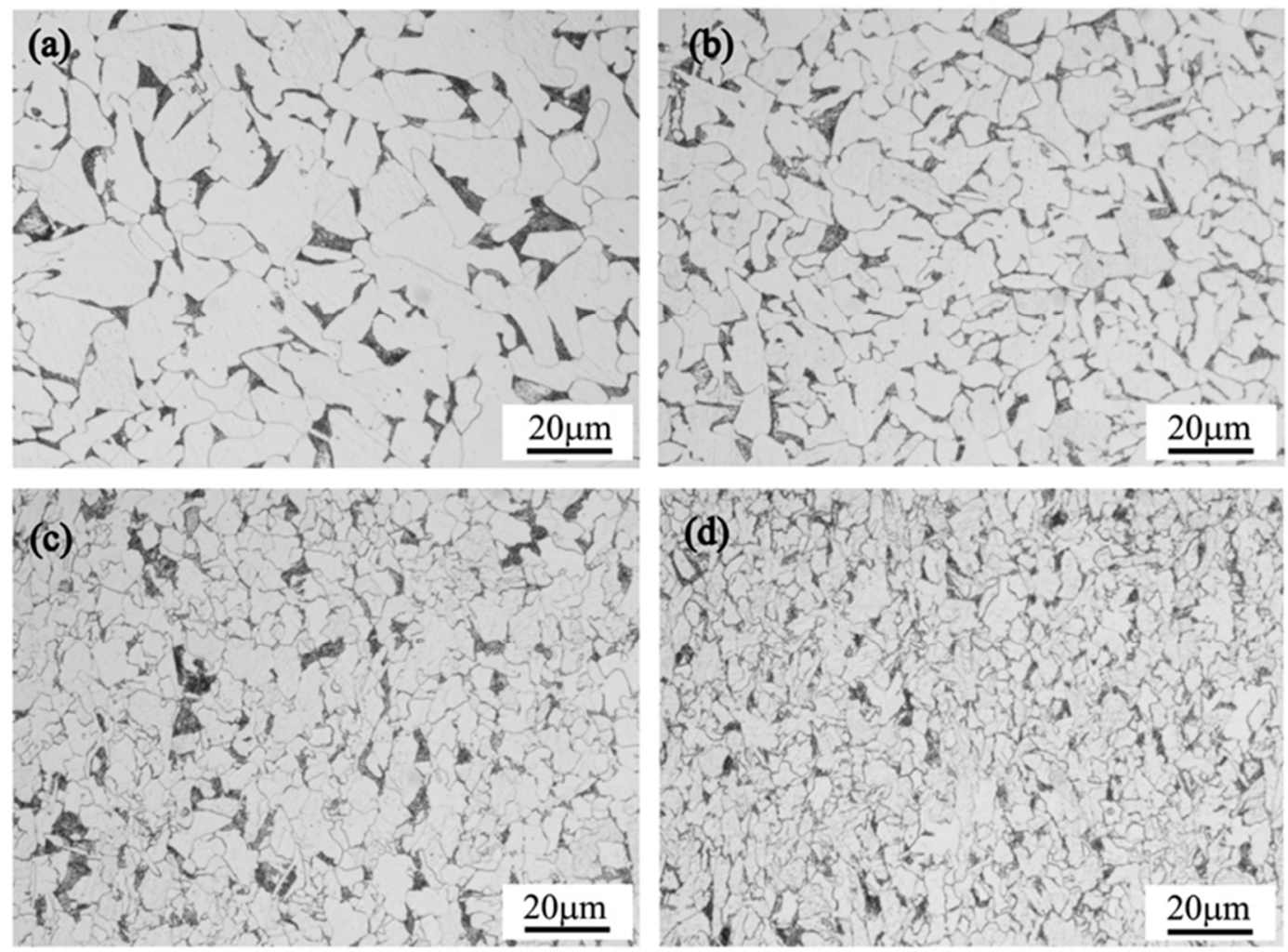

Figure 9. Microstructure of as-rolled steels (a) Q235B (b) Q235BM (c) Q355B (d) Q355BM.

Additionally, modified RE inclusions can also increase corrosion resistance. The inclusions of $\mathrm{MnS}$ and $\mathrm{Al}_{2} \mathrm{O}_{3}$ are commonly observed in traditional low-carbon steels and low-alloy steels, as shown in Figure 10. The inclusion in Q235B steel is mainly composed of long-strip MnS with a size of more than $20 \mu \mathrm{m}$ (Figure 10a), while the main inclusions in Q355B steel are composite inclusions in chains formed by $\mathrm{Al}_{2} \mathrm{O}_{3}$ and $\mathrm{MnS}$ with a size of more than $10 \mu \mathrm{m}$ (Figure 10b). The addition of RE elements into steels can modify the inclusions to form spherical RE-sulfides and (RE, Al)-oxy-sulfides with a smaller size, as shown in the Figure 11. In traditional steels, non-metallic inclusions especially MnS often provide initiation sites for pitting corrosion [21]. Because MnS often acts as a cathode and the matrix acts as an anode in a corrosion system, the oxide film between MnS and the substrate is easily destroyed by aggressive ions. The activated matrix preferentially dissolves to produce Fe $\mathrm{Fe}^{2+}$ around $\mathrm{MnS}$ and then hydrolyzed to produce $\mathrm{H}^{+}$. It is tended to cause local acidification at the interface and promotes the dissolution of $\mathrm{MnS}$, which produces $\mathrm{S}^{2-}$ and $\mathrm{HS}^{-}$to promote further pitting corrosion [35]. $\mathrm{RE}$ can suppress the formation of $\mathrm{MnS}$ and control the size of inclusions, owing to the lower standard 
formation energy of RE inclusions [30]. The interface area between RE inclusions and the matrix is far less than that between MnS and the matrix, so the active area is reduced and weakens micro galvanic corrosion. Results above have also shown that the diameter of inclusion in steels alloyed by RE elements has been decreased to less than $5 \mu \mathrm{m}$ and the shapes are transformed from irregular to spheroid shapes. The dispersed small inclusions can become activated points of corrosion reaction, which is beneficial to the formation of continuous uniform rust layer.
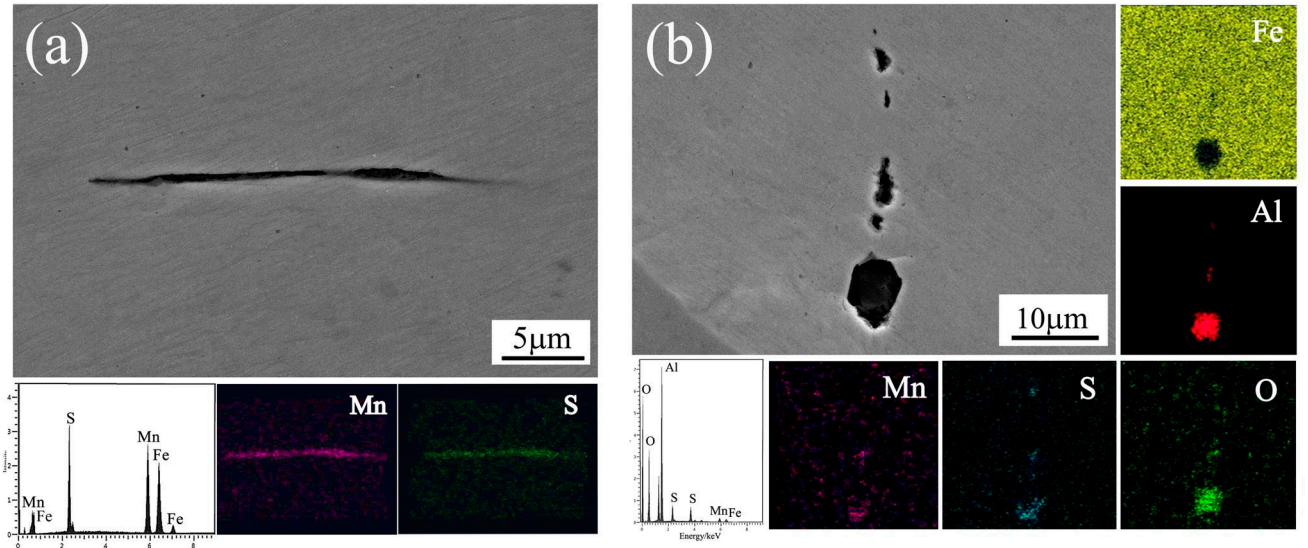

Figure 10. SEM images and EDS mapping of inclusions in (a) Q235B and (b) Q355B.
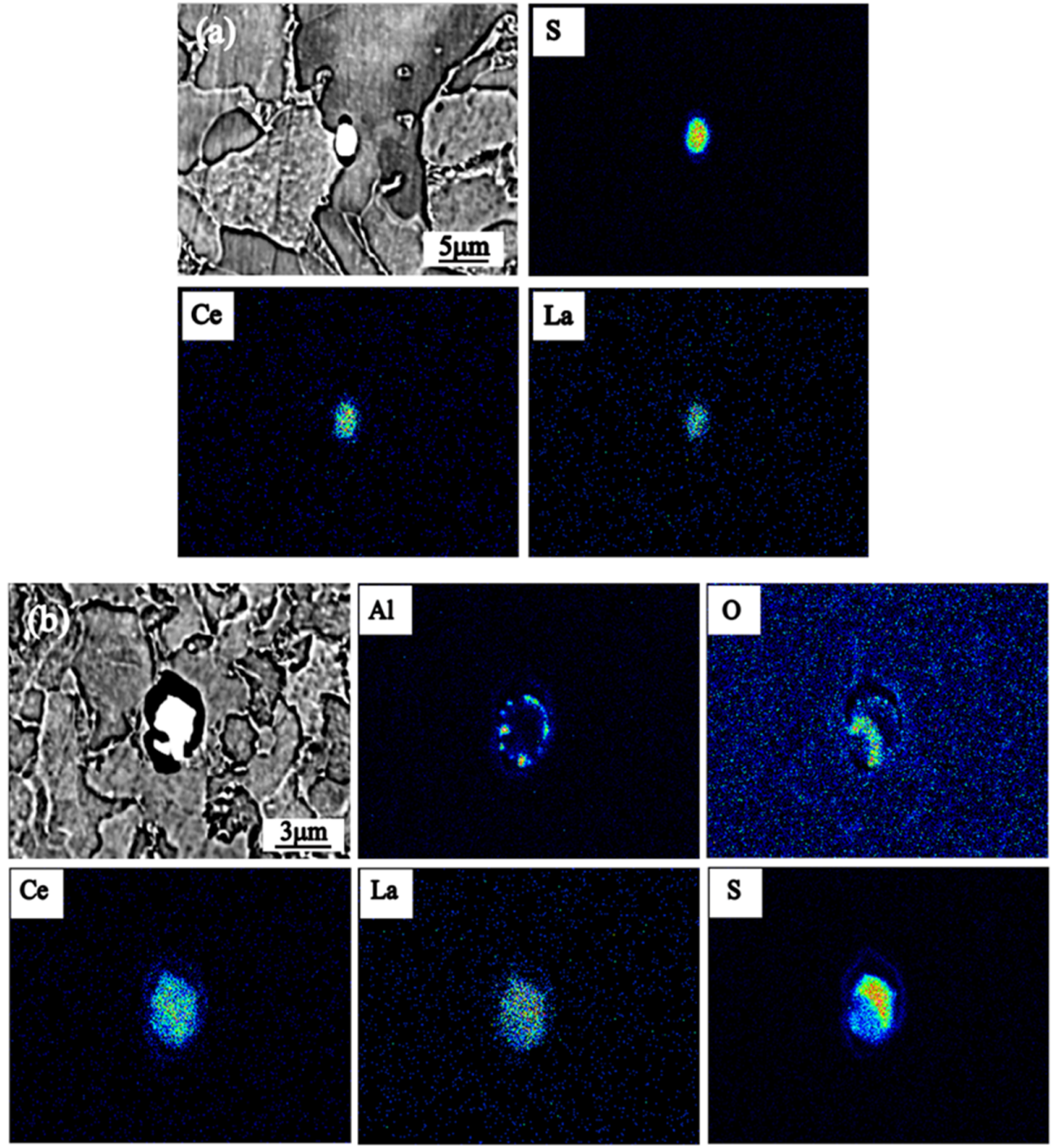

Figure 11. SEM images and EPMA mapping of inclusions in RE-modified (a) Q235BM (b) Q355BM. 


\section{Conclusions}

The effects of RE elements on corrosion properties of Q235B and Q355B steels under wet-dry cycle immersion tests are analyzed. RE elements play an important role in enhancing corrosion performance. Firstly, microstructure is greatly refined by RE alloying, which is beneficial to increase the density of rust layers and thus improve the corrosion resistance. The beneficial effect of RE in optimizing inclusions is to form smaller spherical RE-oxy-sulfides and reduces the occurrence of pitting. Furthermore, segregation of RE towards grain boundaries confirms that RE is likely to accumulate at interfaces with high energies. The segregation of RE between rust layers and the matrix can effectively improve the adhesion of the rust layers and prevents corrosive ions from contacting the matrix. Therefore, low-carbon and low-alloy steels combined with high corrosion resistance via RE alloying can extend the life of steels, showing a promising application as economic structural materials.

Author Contributions: Funding acquisition, H.D.; investigation, R.W.; methodology, T.L. and J.X.; project administration, D.X.; validation, J.Z.; writing-original draft, X.L. All authors have read and agreed to the published version of the manuscript.

Funding: This work was supported by Open Project of State Key Laboratory of Advanced Special Steel, Shanghai Key Laboratory of Advanced Ferrometallurgy, Shanghai University and the Science and Technology Commission of Shanghai Municipality (No. 19DZ2270200).

Conflicts of Interest: The authors declare that they have no known competing financial interest or personal relationship that could have appeared to influence the work reported in this paper.

\section{References}

1. Seifert, H.P.; Hickling, J.; Lister, D. Corrosion and Environmentally-Assisted Cracking of Carbon and Low-Alloy Steels; Elsevier: Oxford, UK, 2012; pp. 105-142.

2. Tait, W.S. Handbook of Environmental Degradation of Materials, 2nd ed.; William Andrew Publishing: New York, NY, USA, 2012; pp. 863-886.

3. Zhou, Y.L.; Chen, Y.; Liu, Z.Y. Effects of Cr, Ni and Cu on the Corrosion Behavior of Low Carbon Microalloying Steel in a $\mathrm{Cl}^{-}$Containing Environment. J. Mater. Sci. Technol. 2013, 29, 168-174. [CrossRef]

4. Liu, B.; Liu, L. Improvement of corrosion resistance of Cu-based bulk metallic glasses by the microalloying of Mo. Intermetallics 2007, 15, 679-682. [CrossRef]

5. Morozov, Y.; Calado, L.M.; Shakoor, R.A.; Raj, R.; Kahraman, R.; Taryba, M.G.; Montemor, M.F. Epoxy coatings modified with a new cerium phosphate inhibitor for smart corrosion protection of steel. Corros. Sci. 2019, 159, 108-128. [CrossRef]

6. Xu, D.; Lou, C.; Huang, J.; Lu, X.; Xin, Z.; Zhou, C.L. Effect of inhibitor-loaded halloysite nanotubes on active corrosion protection of polybenzoxazine coatings on mild steel. Pro. Org. Coat. 2019, 134, 126-133. [CrossRef]

7. Morcillo, M.; Dían, I.; Cano, H.; Chico, B.; de la Fuente, D. Atmospheric corrosion of weathering steels. Overview for engineers. Part I: Basic concepts. Constr. Build. Mater. 2019, 213, 723-737. [CrossRef]

8. Rodrigues, C.A.D.; Bandeira, R.M.; Duarte, B.B.; Tremiliosi-Filho, G.; Jorge, A.M., Jr. Effect of phosphorus content on the mechanical, microstructure and corrosion properties of supermartensitic stainless steel. Mat. Sci. Eng. A 2016, 650, 75-83. [CrossRef]

9. Wang, L.M.; Lin, Q.; Ji, J.W.; Lan, D.N. New study concerning development of application of rare earth metals in steels. J. Alloys Compd. 2006, 408-412, 384-386. [CrossRef]

10. Deng, X.X.; Jiang, M.; Wang, X.H. Mechanisms of inclusion evolution and intra-granular acicular ferrite formation in steels containing rare earth elements. Acta Metal. Sin Engl. 2012, 25, 241-248. [CrossRef]

11. Williams, D.E.; Zhu, Y.Y. Explanation for initiation of pitting corrosion of stainless steels at sulfide inclusions. J. Electrochem. Soc. 2000, 147, 1763-1766. [CrossRef]

12. Zheng, S.Q.; Li, C.Y.; Qi, Y.M.; Chen, L.Q.; Chen, C.F. Mechanism of (Mg, Al, Ca)-oxide inclusion-induced pitting corrosion in 316L stainless steel exposed to Sulphur environments containing chloride ion. Corros. Sci. 2013, 67, 20-31. [CrossRef]

13. Torkkeli, J.; Saukkonen, T.; Hänninen, H. Effect of MnS inclusion dissolution on carbon steel stress corrosion cracking in fuel-grade ethanol. Corros. Sci. 2015, 96, 14-22. [CrossRef] 
14. Shibaeva, T.V.; Laurinavichyute, V.K.; Tsirlina, G.A.; Arsenkin, A.M.; Grigorovich, K.V. The effect of microstructure and non-metallic inclusions on corrosion behavior of low carbon steel in chloride containing solutions. Corros. Sci. 2014, 80, 299-308. [CrossRef]

15. Ha, H.Y.; Park, C.J.; Kwon, H.S. Effects of misch metal on the formation of non-metallic inclusions and the associated resistance to pitting corrosion in 25\% Cr duplex stainless steels. Scr. Mater. 2006, 55, 991-994. [CrossRef]

16. Park, I.J.; Lee, S.M.; Kang, M.; Lee, S.; Lee, S.; Lee, Y.K. Pitting corrosion behavior in advanced high strength steels. J. Alloys Compd. 2015, 619, 205-210. [CrossRef]

17. Lu, W.; Liu, H.; Hsu, T.Y.; Xu, Z.Y. Segregation of rare earth during isothermal transformation in low carbon steels. Scripta Metal. Mater. 1993, 29, 273-274. [CrossRef]

18. Guo, Y.; Sun, S.F.; Song, S.H. Effect of minor rare earth cerium addition on the hot ductility of a reactor pressure vessel steel. Results Phys. 2019, 15, 102746. [CrossRef]

19. Song, S.H.; Xu, Y.W.; Chen, X.M.; Jiang, X. Effect of rare earth cerium and impurity tin on the hot ductility of a Cr-Mo low alloy steel. J. Rare Earths 2016, 34, 1062-1068. [CrossRef]

20. Barrett, C.D.; Imandoust, A.; Kadiri, H.E. The effect of rare earth element segregation on grain boundary energy and mobility in magnesium and ensuing texture weakening. Scr. Mater. 2018, 146, 46-50. [CrossRef]

21. Zhang, X.; Wei, W.Z.; Cheng, L.; Liu, J.; Wu, K.M.; Liu, M. Effects of niobium and rare earth elements on microstructure and initial marine corrosion behavior of low-alloy steels. Appl. Surf. Sci. 2019, 475, 83-93. [CrossRef]

22. Qian, Y.H.; Ma, C.H.; Niu, D.; Xu, J.J.; Li, M.S. Influence of alloyed chromium on the atmospheric corrosion resistance of weathering steels. Corros. Sci. 2013, 74, 424-429. [CrossRef]

23. Liu, Z.; Lian, X.T.; Liu, T.S.; Yang, Y.D.; Zhu, J.N.; Dong, H. Effects of rare earth elements on corrosion behaviors of low-carbon steels and weathering steels. Mater. Corros. 2020, 71, 258-266. [CrossRef]

24. Yu, J.X.; Wang, H.K.; Yu, Y.; Luo, Z.; Liu, W.D.; Wang, C.M. Corrosion behavior of X65 pipeline steel: Comparison of wet-Dry cycle and full immersion. Corros. Sci. 2018, 133, 276-287. [CrossRef]

25. Chen, Y.Y.; Tzeng, H.J.; Wei, L.I.; Wang, L.H.; Oung, J.C.; Shih, H.C. Corrosion resistance and mechanical properties of low-alloy steels under atmospheric conditions. Corros. Sci. 2005, 47, 1001-1021. [CrossRef]

26. Wang, Z.F.; Liu, J.R.; Wu, L.X.; Han, R.D.; Sun, Y.Q. Study of the corrosion behavior of weathering steels in atmospheric environments. Corros. Sci. 2013, 67, 1-10. [CrossRef]

27. McGuire, G.E. Auger Electron Spectroscopy Reference Manual; Springer: Boston, MA, USA, 1979; pp. 114-116. [CrossRef]

28. Sánchez-Amaya, J.M.; Blanco, G.; Garcia-Garcia, F.J.; Bethencourt, M.; Botana, F.J. XPS and AES analyses of cerium conversion coatings generated on AA5083 by thermal activation. Surf. Coat. Technol. 2012, 213, 105-116. [CrossRef]

29. Yue, L.J.; Wang, L.M.; Han, J.S. Effects of rare earth on inclusions and corrosion resistance of 10PCuRE weathering steel. J. Rare Earths 2010, 28, 952-956. [CrossRef]

30. Liu, C.; Revilla, R.I.; Liu, Z.Y.; Zhang, D.W.; Li, X.G.; Terryna, H. Effect of inclusions modified by rare earth elements (Ce, La) on localized marine corrosion in Q460NH weathering steel. Corros. Sci. 2017, 129, 82-90. [CrossRef]

31. Szummer, A.; Janik-Czacho, M.; Hofmann, S. Discontinuity of the passivating film at nonmetallic inclusions in stainless steels. Mater. Chem. Phys. 1993, 34, 181-183. [CrossRef]

32. Aghuy, A.A.; Zakeri, M.; Moayed, M.H.; Mazinani, M. Effect of grain size on pitting corrosion of 304L austenitic stainless steel. Corros. Sci. 2015, 94, 368-376. [CrossRef]

33. Ralston, K.D.; Birbilis, N. Effect of grain size on corrosion: A review. Corrosion 2010, 66, 075005-075013. [CrossRef] 
34. Hadzima, B.; Janeček, M.; Estrin, Y.; Kim, H.S. Microstructure and corrosion properties of ultrafine-grained interstitial free steel. Mater. Sci. Eng. A. 2007, 462, 243-247. [CrossRef]

35. Avci, R.; Davis, B.H.; Wolfenden, M.L.; Beech, I.B.; Lucas, K.; Paul, D. Mechanism of MnS-mediated pit initiation and propagation in carbon steel in an anaerobic sulfidogenic media. Corros. Sci. 2013, 76, 267-274. [CrossRef] 